\title{
Repercussões da pandemia da COVID-19 na vida de homens trabalhadores
}

\section{autônomos}

\author{
Repercussions of COVID-19 pandemic on life of men self-employed worker \\ Efectos de la pandemia del COVID-19 en la vida de los hombres trabajadores autónomos
}

Recebido: 26/02/2021 | Revisado: 06/03/2021 | Aceito: 21/06/2021 | Publicado: 04/07/2021

\author{
Jeane Barros de Souza \\ ORCID: https://orcid.org/0000-0002-0512-9765 \\ Universidade Federal da Fronteira Sul, Brasil \\ E-mail: jeane.souza@uffs.edu.br \\ Valéria Silvana Faganello Madureira \\ ORCID: https://orcid.org/0000-0001-7990-3613 \\ Universidade Federal da Fronteira Sul, Brasil \\ E-mail: valeria.madureira@uffs.edu.br \\ Kátia Lilian Sedrez Celich \\ ORCID: https://orcid.org/0000-0002-5166-8444 \\ Universidade Federal da Fronteira Sul, Brasil \\ E-mail: katia.celich@uffs.edu.br \\ Marcela Martins Furlan de Léo \\ ORCID: https://orcid.org/0000-0003-3457-5999 \\ Universidade Federal da Fronteira Sul, Brasil \\ E-mail: marcela.leo@uffs.edu.br \\ Jeferson Santos Araújo \\ ORCID: https://orcid.org/0000-0003-3311-8446 \\ Universidade Federal da Fronteira Sul, Brasil \\ E-mail: jeferson.araujo@uffs.edu.br \\ Vander Monteiro da Conceição \\ ORCID: https://orcid.org/ 0000-0003-0972-0795 \\ Universidade Federal da Fronteira Sul, Brasil \\ E-mail: vander.conceicao@uffs.edu.br
}

\begin{abstract}
Resumo
Objetivo: compreender as repercussões da pandemia COVID-19 na vida de homens que são profissionais autônomos. Método: estudo qualitativo, tipo ação-participante, fundamentado no referencial teórico metodológico de Paulo Freire. Utilizou-se o Círculo de Cultura Virtual estabelecendo analogia entre as etapas do Itinerário de Pesquisa Freireano e o carro, correspondendo: Investigação Temática à lataria; Codificação e Descodificação ao motor; Desvelamento Crítico aos pneus. Em julho de 2020 realizou-se um Círculo de Cultura com a participação de 15 homens trabalhadores autônomos, de diferentes regiões do Brasil, que foram selecionados pelo método Snowball. Resultados: a Investigação Temática resultou em dois temas geradores. O primeiro, medos da COVID-19, destacaram-se questões econômicas dos participantes, do país, repercussões sobre o futuro e o medo de perder pessoas queridas. O segundo tema, impactos da COVID-19 na saúde do homem, desvelaram-se os efeitos sobre a saúde mental, o viver em casal, ganho de peso, desesperança e outras preocupações. Conclusão: as temáticas expõem à ameaça da pandemia sobre a masculinidade hegemônica, à qual é vetado sentir-se vulnerável e inseguro. O Círculo de Cultura Virtual criou um espaço de cuidado para que os homens falassem de si e de suas vidas.
\end{abstract}

Palavras-chave: Saúde do homem; COVID-19; Isolamento social; Promoção da saúde.

\begin{abstract}
Objective: to comprehend the repercussions of the COVID-19 pandemic on the lives of men who are self-employed professionals. Method: qualitative, action-participant study, based on Paulo Freire's theoretical and methodological framework. The Virtual Culture Circle was used, establishing an analogy between the stages of the Freirean Research Itinerary and the car, corresponding to: Thematic Investigation to the bodywork; Engine encoding and decoding; Critical unveiling of tires. In July 2020, a Culture Circle was held with the participation of 15 men self-employed worker, from different regions of Brazil, that were included by the Snowball method. Results: Thematic Research resulted in two generating themes. The first, COVID-19's fears, highlighted economic issues of the participants, the country, repercussions on the future and the fear of losing loved ones. The second theme, impacts of COVID-19 on men's health, revealed the effects on mental health, living as a couple, weight gain, hopelessness and other concerns. Conclusion: the themes expose the menace of the pandemic to hegemonic masculinity, which is forbidden to feel
\end{abstract}


vulnerable and insecure. The Virtual Culture Circle created a space of care for men to talk about themselves and their lives.

Keywords: Men's health; COVID-19; Social isolation; Health promotion.

\begin{abstract}
Resumen
Objetivo: comprender los efectos de la pandemia COVID-19 en la vida de los hombres que trabajan por cuenta propia. Método: estudio cualitativo, acción-participante, basado en el marco teórico y metodológico de Paulo Freire. Se utilizó el Círculo de Cultura Virtual, estableciendo una analogía entre las etapas del Itinerario de Investigación Freireano y el automóvil, correspondiente a: Investigación Temática a la carrocería; Codificación y decodificación de motores; Revelación crítica de neumáticos. En julio de 2020, se realizó un Círculo de Cultura con la participación de 15 hombres trabajadores autónomos, de diferentes regiones de Brasil, que fueron incluidos por el método Snowball. Resultados: La Investigación Temática resultó en dos temas generadores. El primero, los miedos de COVID-19, destacó los problemas económicos de los participantes, el país, las repercusiones en el futuro y el miedo a perder seres queridos. El segundo tema, los impactos del COVID-19 en la salud de los hombres, reveló los efectos sobre la salud mental, la vida en pareja, el aumento de peso, la desesperanza y otras preocupaciones. Conclusión: los temas exponen la amenaza de la pandemia a la masculinidad hegemónica, que está prohibido para sentirse vulnerable e inseguro. El Círculo de Cultura Virtual creó un espacio de atención para que los hombres hablaran de sí mismos y de sus vidas.

Palabras clave: Salud de los hombres; COVID-19; Aislamiento social; Promoción de la salud.
\end{abstract}

\title{
1. Introdução
}

No final do ano de 2019 a humanidade foi surpreendida por uma infecção viral que gerou uma crise mundial sem precedentes. Denominado de Coronavirus Disease 2019 (COVID-19), o vírus se espalhou rapidamente por todos os continentes e, no início de março, a Organização Mundial da Saúde (OMS) decretou que o mundo vivia uma pandemia (WHO, 2020). No Brasil, o Ministério da Saúde sancionou leis (Brasil, 2020; Brasil, 2020), com o intuito de proteger a população para o enfrentamento dos agravos da COVID-19. Dentre os enfoques está a necessidade de isolamento social e distanciamento físico.

O percurso da pandemia tem afetado de maneira singular a vida da população mundial, deixando cicatrizes na vida dos indivíduos. De acordo com Arbis (2020), pode-se evidenciar pelo menos três grandes marcas: a primeira é o alto custo em vidas e sequelas que feriram populações em um curto espaço de tempo; a segunda relaciona-se à aguda recessão e consequente diminuição do emprego, de salários e de renda, fechamento de empresas e desorganização da economia, com aumento das desigualdades e da pobreza; a terceira está vinculada à corrosão institucional e à disseminação do medo e da perplexidade na sociedade. É notório observar a enorme onda de insegurança que percorre os países, o que afetará de maneira duradoura o modo de viver e trabalhar dos indivíduos, com impactos de longa duração na economia mundial, particularmente danosos aos países em desenvolvimento como o Brasil.

Segundo informações da Committee for the Coordination of Statistical Activities (CCSA), até maio, a crise gerada pela COVID-19 havia conduzido para a pobreza extrema cerca de 60 milhões de pessoas e, mesmo em países mais ricos, 36\% das famílias esgotaram seus recursos básicos após três meses sem renda. A perda de renda, do emprego, redução da jornada de trabalho, diminuição salarial ou a impossibilidade de acesso ao mercado (situação especialmente crítica para os trabalhadores informais), já empurrou cerca de 60 milhões de pessoas para a extrema pobreza em todo o mundo (Arbis, 2020).

Nesta situação de incerteza e complexidade encontram-se muitos trabalhadores brasileiros, especialmente os profissionais autônomos, visto que não possuem vínculo empregatício, atuando na prestação de serviço de forma livre. Diante da pandemia da COVID-19 e do impacto econômico dela resultante, o futuro é incerto. As impossibilidades de prover necessidades básicas próprias e de sua família podem acarretar preocupações, ansiedade, medo e sentimento de impotência, situação que pode gerar comprometimento na saúde de todos. Essa situação pode ser especialmente verdadeira para homens que trabalham na condição de autônomos, posto que o trabalho e família são elementos centrais na construção e na vivência da masculinidade hegemônica (Connell \& Messerschmidt, 2020; Trentini, Madureira, Silva \& Paim, 2018).

O termo masculinidades representa a forma como os homens relacionam-se com o mundo, tal termo é sempre 
apresentado no plural por entender-se que não há uma única forma de ser homem, ou seja, as masculinidades são múltiplas e influenciadas pela cultura, política, economia e história. Dentre as masculinidades, a hegemônica é forma de expressão mais conhecida, uma vez que ela compila atributos estereotipados ao homem, como força física, provedor familiar e virilidade, porém é válido ressaltar que poucos homens atendem na íntegra a este padrão, e geralmente tais características estão presentes nos discursos deles, mas não na prática cotidiana (Nascimento \& Connell, 2021).

Nesse sentido, as restrições decorrentes do avanço da COVID-19 no Brasil repercutem diretamente sobre a masculinidade, à medida que interdita as relações interpessoais impondo distanciamento físico, o acesso aos locais de trabalho e, mesmo, a manutenção de uma atividade laboral que assegure proventos. Assim, acredita-se ser imprescindível a atenção dos enfermeiros e demais profissionais de saúde a homens trabalhadores, pois de modo geral, na perspectiva cultural, social e histórica, este público não têm o hábito de procurar os serviços de saúde preventivamente (Brasil, 2018). Nesse cenário, urge a necessidade de lançar um olhar específico para este segmento populacional, especialmente durante esta fase pandêmica, já que os homens representam um contingente de mais de 100 milhões de pessoas no território brasileiro (IBGE, 2019), o que representa $48,2 \%$ da população.

Portanto, este estudo se justifica por refletir acerca do olhar dos homens sobre si, no que se refere as repercussões da COVID-19, pois a concepção de que este público é invulnerável pode colocá-lo em maior risco ao vírus, bem como, a resistir o cumprimento do distanciamento social. Nessa conjuntura pandêmica, é premente compreender tais repercussões na saúde dos homens, com o intuito de subsidiar as ações para promover a saúde e atuar na redução de danos de maneira intersetorial sobre o público masculino (Sousa et al., 2021).

Diante do exposto, questionou-se: quais as repercussões da pandemia COVID-19 na saúde de homens que são profissionais autônomos? Assim, o objetivo do estudo foi compreender as repercussões da pandemia COVID-19 na vida de homens que são profissionais autônomos.

\section{Metodologia}

Estudo qualitativo (Pereira et al., 2018), do tipo pesquisa ação-participante (Felcher, Ferreira \& Folmer, 2017), fundamentado no referencial teórico metodológico de Paulo Freire. Percorreu-se o Itinerário de Pesquisa Freireano, que é composto por três fases que são interligadas entre si de maneira proativa e dialética: Investigação Temática; Codificação e Descodificação; e Desvelamento Crítico (Heidemann et al., 2017; Dalmolin \& Heidemann, 2020).

A Investigação Temática consiste no diálogo inicial com a finalidade de identificar os temas geradores, que emergem de acordo com a realidade dos participantes da pesquisa. A Codificação aAe Descodificação é o momento em que os temas geradores são refletivos, o que representa as situações existenciais com olhar crítico sobre a realidade vivida. O Desvelamento Crítico é a fase em que a consciência crítica da situação existencial ocorre, em que se vislumbra os limites e as possibilidades da realidade (Heidemann et al., 2017).

As etapas do Itinerário de Pesquisa ocorrem em espaço denominado Círculo de Cultura O Círculo de Cultura envolve a práxis dialógica de um grupo de pessoas com interesse em comum, em um processo participativo e de relações horizontalizadas, mediado por um facilitador que problematiza os temas geradores. Neste espaço há oportunidade para trocas e construção de saber a partir da discussão de problemas e situações de vida por todos os participantes, os quais se enriquecem com reflexões sobre a realidade, em busca de transformação (Heidemann et al., 2017; Dalmolin \& Heidemann, 2020).

Com o cenário pandêmico optou-se em realizar o Círculo de Cultura virtualmente, suscitando uma inovação na condução de tal prática, à qual denominou-se Círculo de Cultura Virtual (CCV). Para tanto, utilizou-se o aplicativo Google Meet ${ }^{\circledR}$ que, por meio de dispositivos eletrônicos, possibilitou a integração e aproximação dos participantes do estudo, mesmo distantes fisicamente. 
Foram incluídos 15 homens, que residiam em diferentes locais do Brasil. Os critérios de inclusão foram: homens com idade superior a 18 anos, que se identificassem como profissionais autônomos. Os critérios de exclusão envolveram homens sem acesso à internet e dispositivos eletrônicos durante a realização do estudo.

Utilizou-se o método de amostragem Snowball para seleção dos participantes do estudo (Ghaljaie, Naderifar \& Goli, 2017). Assim, um homem profissional autônomo conhecido dos pesquisadores, foi convidado por meio de mensagem no WhatsApp ${ }^{\circledR}$ a integrar a pesquisa. Este homem convidou outro amigo para participar do estudo e assim sucessivamente, até obtenção dos 15 participantes. Optou-se por esse número máximo a fim de possibilitar a prática dialógica virtual concernente ao método escolhido, pois um número maior de pessoas poderia dificultar a interação e o diálogo entre os envolvidos.

Para tanto, organizou-se um grupo no WhatsApp ${ }^{\circledR}$, com a participação dos 15 homens e equipe de pesquisa para facilitar o contato. Nesse grupo questionou-se sobre um objeto que os homens utilizavam intensamente e juntos, decidiram pelo uso do carro. Somado a isso, decidiram o melhor dia e horário para se encontrarem virtualmente. A partir de então, foi realizado um CCV no dia 30 de julho de 2020 no período noturno, com duração de aproximadamente duas horas e meia, tendo como mediadora uma enfermeira pesquisadora experiente na condução do método.

Contou-se com o apoio do diário de campo para registro dos temas geradores que emergiram durante o encontro, que foi gravado com o devido consentimento dos participantes. Para condução do CCV, a fim de manter interatividade durante o percurso do Itinerário de Pesquisa, realizou-se uma analogia com o carro, escolhido pelos próprios participantes, com vistas a instigar a participação dos homens por meio de algo concreto e do cotidiano deles, conforme demonstração da Figura 1.

Figura 1. Itinerário de Pesquisa de Paulo Freire com homens trabalhadores autônomos: analogia com o carro. Chapecó, SC, Brasil, 2020.

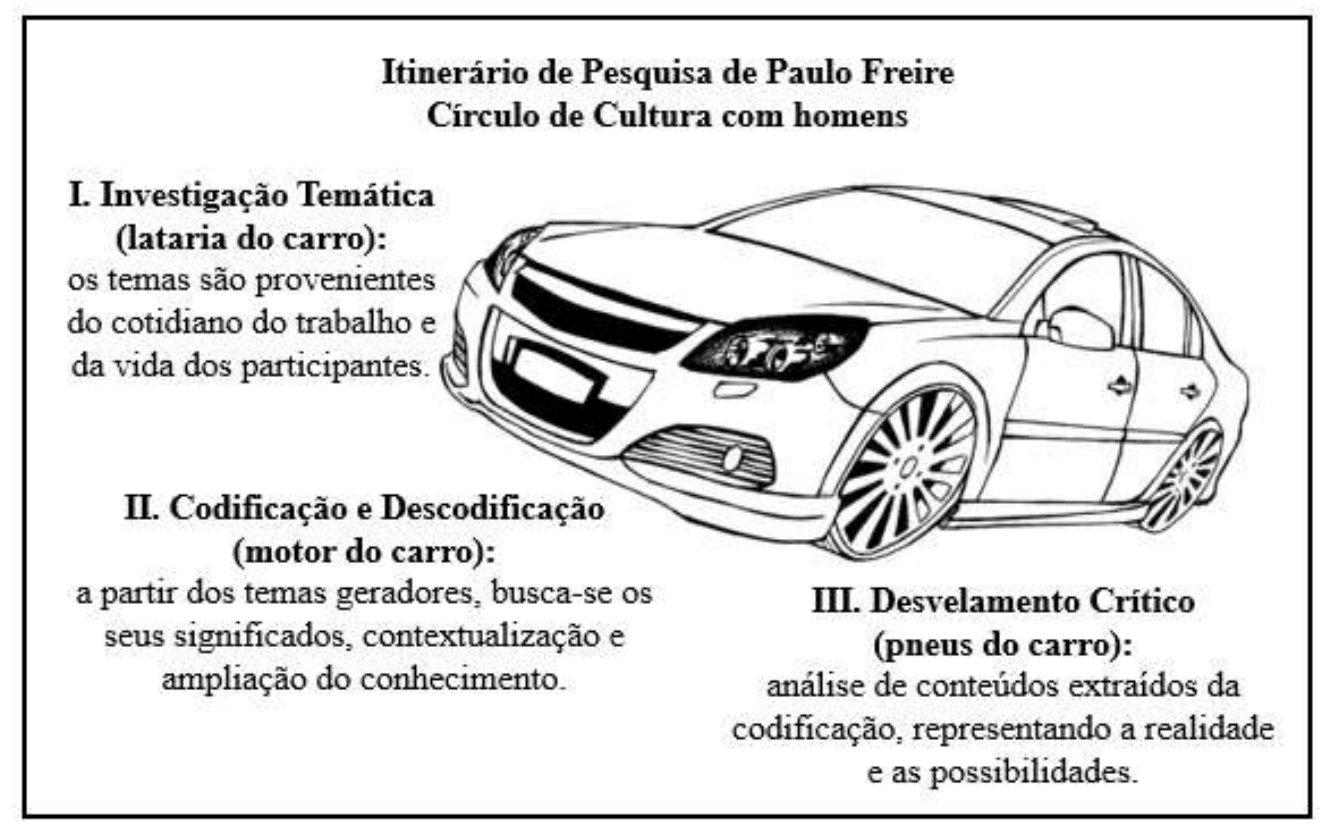

Fonte: Autores a partir de: https://desenhodes.blogspot.com/2018/04/desenhos-de-carros-preto-e-branco.html

Na Investigação Temática (Fase I), a mediadora falou sobre os desafios inerentes à compra de um carro, em que se realiza várias investigações, como observar a lataria, a procura de avarias, buscando-se identificar esteticamente a sanidade do objeto. Estabeleceu analogia entre essa etapa da compra de um carro com a responsabilidade social dos pesquisadores, que investigam as repercussões da COVID-19 na saúde dos brasileiros, em especial de homens profissionais autônomos, ressaltando que algum comprometimento da vida desse público salta aos olhos com a progressão da pandemia. Para instigar o 
diálogo, lançou-se o seguinte questionamento: quais as repercussões da pandemia COVID-19 na saúde dos homens?

Os participantes do estudo discutiram intensamente acerca das repercussões da pandemia em suas vidas, partilhando vivências. Diante das reflexões, o grupo elegeu dois temas geradores para dialogar e aprofundar discussões: 1) Os medos da COVID-19; e 2) COVID-19 e os impactos na saúde do homem.

Para a Codificação e Descodificação (Fase II), a mediadora destacou que, para um carro se deslocar com fluidez, há necessidade de revisar seu motor, apontando que também se fazia necessário revisar e aprofundar os dois temas geradores. Assim, projetou na tela do dispositivo eletrônico um carro e, de um lado, descreveu o primeiro tema gerador e, do outro, registrou o segundo tema para discussão. Primeiramente os questionou: quais os medos que a COVID-19 despertou em você? Todos os participantes responderam, enquanto a mediadora foi anotando seus depoimentos na tela por meio de uma palavrachave. Posteriormente, os questionou: quais são os impactos da COVID-19 para a sua saúde? Os homens responderam ao segundo questionamento, dialogando intensamente entre si e complementando-se mutuamente, enquanto a mediadora registrava suas percepções na tela, como se evidencia na Figura 2.

Figura 2. Representação da Codificação e Descodificação dos dois temas geradores no Círculo de Cultura Virtual. Chapecó, SC, Brasil, 2020.

\section{Representação da codificação e descodificação dos dois temas geradores no CCV}

\begin{tabular}{ll} 
1) Os medos da COVID-19 & 2) COVID-19 e os impactos na saúde \\
& \\
Não conseguir sustentar a família & \\
Perder todo o investimento financeiro & Preocuade \\
Nunca mais ter o que se perdeu & Preocupação com a sua saúde \\
Falta de dinheiro & Preocupação com a saúde da família \\
Falta de oportunidades para recomeçar & Depressão \\
Pais morrerem de COVID-19 & Choro \\
A doença e suas repercussões & Falta de sono \\
Mundo não voltar como era antes & Ganho de peso \\
Fake News & Separação do casal \\
Situação politica do país & Acúmulo de notícias desagradáveis \\
Situação econômica do país & Estresse \\
Não poder abraçar as pessoas que ama & Desmotivação \\
Fechar a empresa definitivamente & Não saber o que fazer \\
Ter que demitir todos os funcionários & Desesperança \\
Não se reerguer daqui para frente & Desânimo para recomeçar \\
\hline
\end{tabular}

Fonte: Autores a partir de: https://desenhodes.blogspot.com/2018/04/desenhos-de-carros-preto-e-branco.html

Para validar as anotações referentes às codificações e descodificações dos temas geradores, a mediadora leu todos os termos registrados para os homens, incentivando-os a refletir novamente sobre as temáticas, com vistas a selar o processo de ação-reflexão, buscando instigá-los a compreender sua capacidade de enfrentar os desafios levantados (Dalmolin, Heidemann, 2020).

No desenvolvimento do Desvelamento Crítico, Fase III do Itinerário de Pesquisa, a mediadora destacou a importância dos pneus dos carros para garantir um trajeto seguro, convidando os participantes a (re)significar as temáticas sobre as repercussões da pandemia COVID-19 em suas vidas, oportunizando a eles trazer para nível consciente a situação social, sanitária e econômica real, bem como a partilha de experiências para fortalecimento mútuo, em busca de estratégias para percorrer a trajetória da vida e transformar sua realidade atual. 
Em seguida, a mediadora perguntou qual foi a percepção dos homens sobre sua participação no CCV durante a conjuntura pandêmica, viabilizando um momento para refletirem sobre a experiência de terem parado por alguns instantes para dialogar sobre o tema, como oportunidade de promover a sua saúde.

Ao término do $\mathrm{CCV}$, os diálogos foram imediatamente transcritos e ficaram organizados em pastas digitais, conforme os temas geradores discutidos durante o encontro. Cabe ainda salientar que a análise dos temas (dados) foi realizada juntamente com o desenvolvimento do CCV, como previsto no Itinerário de Pesquisa de Paulo Freire.

A pesquisa seguiu os preceitos éticos da Resolução 466 de 2012. O TCLE foi encaminhado para os homens, que o assinaram e o devolveram para os pesquisadores via e-mail. Os nomes dos participantes foram codificados a partir de modelos de carros, a fim de garantir sigilo, preservando seu anonimato. O estudo iniciou-se somente após aprovação pelo Comitê de Ética em Pesquisa com Seres Humanos, com parecer número 4.068.387 de três de junho de 2020.

\section{Resultados}

A idade dos participantes variou entre 28 e 56 anos. Todos eram casados com mulheres, sendo que um deles estava recentemente separado da esposa. Tinham filhos em diversas fases da vida. Residiam em diferentes localidades do Brasil, sendo: cinco em Santa Catarina, três em São Paulo, dois no Paraná, um no Ceará, dois no Rio Grande do Sul e dois no Rio de Janeiro. Atuavam em diferentes ramos profissionais, tais como: vendas de produtos farmacêuticos e tecnológicos, comercio (lojas) de capinhas de celular e de roupas, alimentação (restaurante e pizzaria), marketing digital, transporte escolar e fotógrafo. A renda mensal dos participantes, antes da pandemia, era entre quatro e quinze salários-mínimos. Mas com o início da conjuntura pandêmica, todos os participantes referiram decréscimo na sua renda mensal.

Durante os diálogos sobre o primeiro tema gerador, 'os medos da COVID-19', os homens reportaram a perda de suas economias e investimentos financeiros durante a pandemia, o que lhes provocou a preocupação de nunca mais reobter o que já haviam conquistado, bem como o receio de não se reerguerem diante da crise financeira decorrente da pandemia. Esse cenário traz outra preocupação, a de não terem condições de sustentar a família posteriormente:

Eu perdi muito dinheiro. Todas minhas economias e investimentos se foram. Já nem sei dizer e nem calcular o quanto perdi e continuarei perdendo (Tracker).

Tenho medo de nunca mais ter a vida que eu tinha antes e de dar o conforto que eu dava para minha família. Tenho medo de não conseguir me reerguer mais (Duster).

Tenho medo porque não sei como será daqui pra frente e não sei se vou conseguir sustentar a minha família (Camaro).

A preocupação com demissões foi manifestada com referência ao medo de terem que encerrar definitivamente seus negócios e de demitir todos os funcionários, bem como ao fato de já ter havido necessidade de demitir funcionários antigos por falta, no cenário atual, de condições financeiras para arcar com os encargos somados a todas as demais demandas cotidianas:

Eu vou ter que fechar a pizzaria definitivamente porque não estou conseguindo girar dinheiro e manter as contas em dia. Fico preocupado com meus funcionários, com medo de eles não conseguirem manter suas famílias. Não está fácil (Fluence).

Infelizmente eu tive que demitir meus funcionários e foi muito triste tudo isso (Jetta).

Foi discutido sobre o medo da situação política e econômica do Brasil, refletindo que falta apoio governamental efetivo para os profissionais autônomos recomeçarem seus negócios: 
Tenho medo dessa situação política do nosso Brasil. Difícil porque parece que muitas pessoas querem que tudo dê errado e se esquecem que todos moramos no Brasil. Ele é nosso, independente de quem está governando. Precisamos lutar juntos pelo bem do nosso país (Bravo).

Falta apoio do setor econômico. Assim como nós, tem agora inúmeros homens, mulheres, famílias desesperadas, sem saber o que fazer devido a dificuldades econômicas. Algo precisa ser feito para trazer, de fato, condições de a gente se reerguer diante dessa crise imensa (Fusion).

Os homens dialogaram sobre o medo da doença e de suas amplas repercussões. Além disso, também os preocupa o risco de morte de seus pais, já em idade avançada, devido à COVID-19:

Acho que todo mundo está com medo dessa doença e das consequências que a pandemia tem gerado na nossa vida, que deu uma reviravolta total (Camaro).

Tenho medo de meus pais, que estão idosos. Tenho medo de eles ficarem doentes e morrerem dessa COVID-19 (Sentra).

As fakes news também foram citadas como geradoras de medo entre os homens, mais especificamente condizente com o temor de serem afetados por notícias desagradáveis e falsas. Afirmaram sentir medo de que o mundo não volte a ser como era antes e se ressentiram por não poderem abraçar as pessoas que amam:

Tem muita notícia ruim, mentirosa e tenho medo disso. Essas fake news nunca estiveram tão presentes e isso dá medo na gente porque, às vezes, eu acho que todos os brasileiros não sabem nem em quem acreditar (Civic).

Eu fico com medo de o mundo não voltar a ser como era antes. Será que a gente vai poder abraçar as pessoas que amamos, como sempre fazíamos, de uma maneira tranquila? Será que poderemos logo sair sem máscaras? (Corolla).

No segundo tema gerador, em que se discutiu os impactos da COVID-19 na saúde do homem, os participantes afirmaram que a pandemia afetou profundamente sua saúde mental, o que verbalizaram como medo, ansiedade, choro, desmotivação, desesperança, desânimo, ganho de peso e depressão diante do acúmulo de notícias desagradáveis:

Eu ultimamente choro muito, estou ansioso, desmotivado e estressado com tanta coisa pra resolver (Veloster).

É um somatório de notícias desagradáveis, que vai desmotivando a gente e nos falta esperança pra recomeçar. Eu acho que estou com depressão (Kicks).

Eu já era depressivo e, agora, piorou minha situação com tudo isso acontecendo. Estou tomando mais remédios e ganhando bastante peso. Estou bem desanimado! (Frontier).

Somado a isso, os homens referiram preocupações com sua própria saúde, da família, com o futuro, além de se sentirem indecisos sobre o que fazer diante de tantos problemas a resolver, o que tem causado estresse e comprometido seus sonos:

A gente fica preocupado com a família, em ficar doente, em a gente pegar essa doença porque precisamos trabalhar (T-Cross).

Eu estou preocupado com o futuro porque não sei como será daqui pra frente (Duster).

São tantas preocupações todos os dias, que eu perco o sono e não estou conseguindo dormir direito. Acordo todos os dias já cansado e estressado (Fusion). 
Um participante revelou que não conseguiu administrar o somatório de problemas, o que teria repercutido no término do seu casamento em plena pandemia, prejudicando sua saúde. Nessa fala, sinalizou que já enfrentava dificuldades conjugais e ponderou a atual conjuntura como percalço decisivo para a separação:

(...) antes dessa pandemia, eu já estava com alguns problemas no meu casamento, mas com esse tanto de coisa acontecendo ao mesmo tempo, foi a gota d'água pra desandar tudo e a situação piorou porque eu só vivia estressado, sem paciência. Não sei se é definitivo ainda, mas no momento, estou separado e meus filhos estão com minha exesposa. Tudo isso está piorando a minha saúde, minha pressão vive lá nas alturas agora (Frontier).

Os homens compartilharam a importância da experiência de participar do CCV, comparando a atividade com o que denominaram "terapia em grupo", em que todos foram ouvidos e ouviram uns aos outros. Nesse falar e ouvir, sentiram-se encorajados a prosseguir, pois identificaram suas percepções nas falas de vários outros homens que vivenciavam situações semelhantes. Segundo eles, o CCV possibilitou o compartilhamento de experiências, oportunizou aprendizagem, transformação, gratidão e reflexão sobre o viver:

Participar desse encontro foi igual uma terapia em grupo. Me fez muito bem porque parece que estou mais animado. Foi muito positivo. Agradeço a todos (Camaro).

Ao conversarmos aqui percebi que não estou sozinho, que tem mais homens exatamente como eu, sentindo o que estou sentindo e me fez perceber que a gente pode continuar a vida e a lutar em busca de resolver os problemas, um por vez (Corolla).

Foi muito bom pra todo mundo porque, ao trocarmos nossas experiências, a gente conseguiu ajudar um ao outro, me deu ânimo. Eu estava precisando disso, então, só tenho a agradecer! (Tracker)

Eu quero agradecer porque aprendi com todos vocês. Obrigado à enfermeira que nos convidou, que nos proporcionou esse momento de discussão. Eu estou mais animado, ainda com muitos problemas pra resolver, mas parece que com uma luz no fim do túnel, com mais esperança de que o mundo não vai acabar e que a gente vai vencer essas situações difíceis (T-Cross).

\section{Discussão}

Ser homem e trabalhar de forma autônoma no Brasil no período de pandemia é um fenômeno que perpassa diversas questões identitárias, econômicas e morais. A primeira dessa, imprime afirmar que os homens acessaram suas emoções, revelando temores quanto ao papel de trabalhador/provedor familiar, o que lhes desperta tensão, medo e incertezas quanto ao futuro, uma vez que esse apresenta-se incerto devido a medidas compulsórias protecionistas de afastamento do trabalho impostas pelas entidades governamentais, aumentando assim o desemprego e a escassez financeira em seus lares (Bezerra $e t$ al., 2020).

Um estudo realizado pela Fundação Oswaldo Cruz (2020), que envolveu 44.062 pessoas de diversas regiões do Brasil, entre abril e maio de 2020, revelou que 55,0\% dos participantes referiram redução na renda familiar. Por mais que medidas econômicas estejam sendo anunciadas em constante curso no Brasil, juntamente com outras estratégias de enfrentamento da COVID-19, a recessão e a vivência real da privação do trabalho em homens trabalhadores autônomos apontam como distante um cenário de conforto masculino. Os homens compartilham uma cultura valorativa de comportamentos hegemônicos que aporta o domínio sobre as emoções e a responsabilidade pelo provento dos seus entes como elementos de sua masculinidade (Messerschmidt, 2019; Berdahl et al., 2018). Assim, frente ao contexto da pandemia, o masculino sofre um deslocamento dos comportamentos hegemônicos e os homens vivenciam sentimentos mais empáticos e solidários, se conectando com reflexões 
mais profundas sobre seus comportamentos.

Ainda que esse deslocamento possa representar uma transformação desejável nas relações sociais pautada em outras possibilidades de ser homem em uma sociedade plural que clama por sensibilidade, solidariedade e empatia, o impacto dessa mobilização de estrutura masculina pode ser sofrível para quem a vivencia, como pode ser evidenciado pelos depoimentos, que revelam sintomas de sofrimento mental e moral. Os relatos sinalizam que o movimento de transformação da figura hegemônica masculina, nesse grupo estudado, pode ser catalisado pela conjuntura de medo generalizado que se impõe frente ao contágio da doença, que afeta sua capacidade para trabalhar, a sua potência, a sua virilidade - considerando-se que o trabalho está intimamente associado a virilidade, enquanto representações sociais sobre o universo masculino.

Historicamente, o homem requer ser reconhecido pelo coletivo como valente, destemido, forte, herói e segue, assim, em defesa de sua virilidade, também, por meio de seu desempenho no mundo do trabalho; o mundo do trabalho que o convida a criar, a transformar elementos e a sua própria história (Souza \& Antloga, 2017). A psicodinâmica do trabalho contribui com essa compreensão ao destacar o papel de trabalhador como questão de gênero, ressaltando que a satisfação e o sofrimento no mundo do trabalho se manifestam de forma peculiar entre masculino e feminino.

O presente estudo se debruçou sobre a questão do homem no trabalho autônomo, com vistas a lançar luz sobre um público vulnerável no processo saúde-doença-cuidado, que resiste a intervenções em saúde e psicossociais em defesa de sua virilidade. $\mathrm{O}$ homem habitualmente resiste a expressar suas emoções, sobretudo suas fragilidades, ainda que sustentar uma imagem intocável e uma honra viril custe sua saúde e seu bem-estar. Esse fato motivou a estruturação da Política Nacional de Atenção à Saúde do Homem (Brasil, 2008; Batista, Saldanha \& Furtado, 2017), que tenta instrumentalizar a Rede de Atenção em Saúde para se aproximar dos símbolos/códigos predominantemente masculinos e para desenvolver estratégias específicas que fomentem o autocuidado e o comportamento de saúde nesse público.

Competir no mercado, manter um status de empregado e obter vantagens econômicas estão associados ao prazer e saúde no trabalho (Souza \& Antloga, 2017), em contraste com a posição em que se apresentam os participantes, ameaçados pela crise, notavelmente em condição de sofrimento e prejuízo da sua saúde. As fakes news também foram apontadas como elementos que endossam os medos e preocupações masculinas neste período, estigmatizam a doença e prejudicam o acesso da população a informações corretas para a manutenção do distanciamento social, restabelecimento econômico e promoção do autocuidado à saúde (Kadam \& Atre, 2020).

O enfrentamento da COVID-19 repercutiu em desafios para a vida conjugal, como maior dificuldade na comunicação, discussão e no compromisso com a relação (Silva et al., 2020), emergindo separações, como destacado por um dos participantes do estudo. Como consequência da COVID-19, também pode desencadear nos homens insegurança, ansiedade, desesperança, incerteza, desmotivação, estresse diante das preocupações com subsistência e em cumprir o seu papel de provedor, o que abala a saúde da população masculina. Ainda, cabe salientar que a crescente morbimortalidade de homens pela COVID-19, que se justifica por fatores genéticos, comportamentais e de estilo de vida (Sousa et al., 2020).

O CCV expôs trabalhadores autônomos a um desafio que, em outro cenário, poderia ser rejeitado: o desafio de trazer para a linguagem aquilo que se passa na intimidade. O desafio, na dimensão cultural do masculino, de se deparar com a incapacidade de controlar e de dominar, portanto, de se deparar com a impotência. Neste espaço puderam juntos refletir que a COVID-19 prejudicou sua saúde física, mental, social e familiar (Sousa et al., 2021). A realidade de contágio da COVID-19 atravessou esses homens a tal ponto que eles se submeteram a revelar seus sentimentos, a assumir o medo, a depressão, a insegurança, a tristeza, o estresse, o desânimo, o choro, o ganho de peso, a ansiedade, a insônia, a separação da esposa, a desmotivação e desesperança entre outros homens, igualmente atravessados pelo fenômeno e que, igualmente, precisavam desse espaço de fala, em que se reconheceram em seus pares, na identidade do masculino e na identidade do trabalhador.

Essa confiança que se estabeleceu no CCV, em um único encontro, que os levou a perceber como terapêutico, é um 
importante indicador para que enfermeiros e demais profissionais da saúde intervenham, em termos intersetoriais, sobre o público de homens trabalhadores autônomos no contexto que se estabelece, para promover saúde mental e estratégias de enfrentamento e suporte social, prevenir o adoecimento e para tratar complicações que possam advir, incluindo as psiquiátricas e a acentuação da vulnerabilidade social.

\section{Considerações Finais}

Esta pesquisa revelou diferentes repercussões da COVID-19 na vida dos homens que atuam como profissionais autônomos, os quais relataram situações concretas de medo relacionadas à vida diária no exercício de seus diferentes papeis sociais, como a piora de sua condição financeira e redução das possibilidades de manter sua empresa com seus funcionários. Tais questões impactam diretamente na capacidade de cada um sustentar sua família e nas perspectivas de recuperação futura. A isso alia-se o temor de perder pessoas próximas para a COVID-19, como os pais idosos, e de não poder abraçar as pessoas que amam. Porém, além desses, apontaram medos relacionados à conjuntura econômica e política do país, o que somado à disseminação de notícias falsas e ao temor de perder definitivamente o mundo tal como o conheciam anterior à pandemia, pode impactar potencialmente a sua saúde.

Desvelou-se que a saúde dos homens foi afetada durante o enfrentamento do momento pandêmico, em que emergiu estresse, desânimo, desmotivação, desesperança, ansiedade, choro, depressão, preocupações com o futuro e com a saúde de si próprio e da família, ganho de peso e falta de sono. Ainda, foi citada a experiência da separação conjugal e a insegurança, sem saber o que fazer para manter a subsistência da família.

O desenvolvimento do presente estudo possibilitou um espaço de compartilhar experiências para os homens participantes que, mesmo sem todos se conhecerem anteriormente, se reconheceram na vivência e na fala uns dos outros. O CCV demonstrou ser uma ferramenta importante para promoção da saúde que, ao falarem com os demais, puderam refletir sobre o vivido e ressignificar suas experiências. Nesse sentido, a partir de uma reflexão sociológica e antropológica, os autores do estudo consideram premente que o homem se reconheça e se sinta socialmente reconhecido no labor, como necessidade humana básica de realização pessoal, como necessidade de saúde, afetada, nesse momento, pela realidade sanitária que se impõe em âmbito mundial.

Se almeja que o presente estudo sirva de estímulo para o desenvolvimento de outras investigações que permitam dar voz ao público masculino, este que tem vivenciado diversas repercussões advindas do estado pandêmico, e atualmente, possuem espaços escassos para serem ouvidos por profissionais da saúde e pela sociedade em geral. Assim como, que haja novas investigações sobre as repercussões da COVID-19 na vida dos indivíduos e comunidades, visto ser um fenômeno que merece atenção dos profissionais da saúde, para que se promova saúde de maneira contínua no período pós pandêmico.

\section{Referências}

Arbix, G. (2020). Ciência e Tecnologia em um mundo de ponta-cabeça. Estud. Av, 34(99), 65-76.

Batista, A. T., Saldanha, A. A. W. \& Furtado, F. M. F. (2017). Autoconceito masculino e autocuidado em saúde. Psic., Saúde \& Doenças, 18(3), 859-869.

Berdahl, J. L., Cooper, M., Glick, P., Livingston, R. W. \& Williams, J. C. (2018). Work as a masculinity contest. Journal of Social Issues, 74(3), 422-448.

Bezerra, A. C. V., Silva, C. E. M., Soares, F. R. G. \& Silva, J. A. M. (2020). Factors associated with people's behavior in social isolation during the COVID19 pandemic. Ciênc. saúde coletiva, 25(Supp11), 2411-2421.

Brasil, Ministério da Saúde. (2008). Política Nacional de Atenção Integral à Saúde do Homem: princípios e diretrizes. http://bvsms.saude.gov.br/bvs/publicacoes/politica_nacional_atencao_saude_homem.pdf.

Brasil, Ministério da Saúde. (2018). Política nacional de atenção integral a saúde do homem. https://www.saude.gov.br/images/pdf/2018/novembro/07/livroPol--ticas-2018.pdf.

Connell, R. W. \& Messerschmidt, J. W. (2013). Masculinidade hegemônica: repensando o conceito. Rev. Estud. Fem., 21(1), 241-282. 
Research, Society and Development, v. 10, n. 8, e1910813342, 2021

(CC BY 4.0) | ISSN 2525-3409 | DOI: http://dx.doi.org/10.33448/rsd-v10i8.13342

Dalmolin, I. S. \& Heidemann, I. T. S. B. (2020). Integrative and complementary practices in Primary Care: unveiling health promotion. Rev Latino-am Enferm, 28, e3277.

Felcher, C. D. O., Ferreira, A. L. A. \& Folmer, V. (2017). Da pesquisa-ação à pesquisa participante: discussões a partir de uma investigação desenvolvida no facebook. Experiências em Ensino de Ciências, 12(7), 1-18.

Fundação Oswaldo Cruz. (2020). Convid pesquisa de comportamentos. https://convid.fiocruz.br/index.php?pag=principal.

Ghaljaie, F., Naderifar, M. \& Goli, H. (2017). Snowball Sampling: A Purposeful Method of Sampling in Qualitative Research. Strides Dev Med Educ., 14(3), e67670.

Heidemann, I. T. S. B., Dalmolin, I.S., Rumor, P. C. F., Cypriano, C. C., Costa, M. F. B. N. A. \& Durand, M. K.(2017). Reflections on Paulo Freire's research itinerary: contributions to health. Texto Contexto Enferm., 26(4), e0680017.

IBGE, Pesquisa Nacional por Amostra de Domicílios Contínua. (2019). Características gerais dos domicílios e dos moradores 2019. https://biblioteca.ibge.gov.br/visualizacao/livros/liv101707_informativo.pdf.

Kadam, A. B. \& Atre, S. R. (2020). Social media panic and COVID-19 in India: Negative impact of social media panic during the COVID-19 outbreak in India - letter to the editor. Journal of Travel Medicine., 27(3), 1-51.

Lei $n^{\circ} 13.979$, de 06 de fevereiro de 2020. (2020). Dispõe sobre as medidas para enfrentamento da emergência de saúde pública de importância internacional decorrente do coronavírus responsável pelo surto de 2019. Brasília, DF. Retrieved from http://www.planalto.gov.br/ccivil_03/_ato20192022/2020/lei/113979.htm.

Messerschmidt, J. W. (2019). The Salience of "Hegemonic Masculinity.” Men and Masculinities., 22(1), 85-91.

Nascimento, M. \& Connell, R. (2017). Reflecting on twenty years of Masculinities: an interview with Raewyn Connell. Ciênc. saúde coletiva, 22(12), 39753980 .

Pereira A.S. et al. (2018). Metodologia da pesquisa científica. UFSM. https://repositorio.ufsm.br/bitstream/handle/1/15824/Lic_Computacao_MetodologiaPesquisa-Cientifica.pdf?sequence $=1$

Portaria $n^{\circ}$ 454, de 20 de março de 2020. (2020) Declara, em todo o território nacional, o estado de transmissão comunitária do coronavírus (COVID-19). Brasília, DF. http://www.planalto.gov.br/ccivil_03/portaria/prt454-20-ms.htm.

Silva, I. M., Schmidt, B., Lordello, S. R., Noal, D. S., Crepaldi, M. A. \& Wagner, A. (2020). As relações familiares diante da COVID-19: recursos, riscos e implicações para a prática da terapia de casal e família. Pensando familias, 24(1), 12-28.

Sousa, A. R., Carvalho, E. S. S., Silva, T., Sousa, A. F. L., Figueiredo, T. F. G., Escobar, O. J. V., Mota, T. N. \& Pereira, A. (2020). Sentimento e emoções de homens no enquadramento da doença COVID-19. Ciência \& Saúde Coletiva, 25(9), 3481-3491.

Sousa, A. R., Santana, T. S., Carvalho, E. S. S., Mendes, I. A. C., Santos, M. B., Reis, J. L., Silva, A.V. \& Sousa, A. F. L. (2021) Vulnerabilities perceived by men in the context of the COVID-19 pandemic. Rev Rene., 22, e60296.

Souza, R. G. \& Antloga, C. S. (2017). Psicodinâmica do trabalho masculino e a defesa da virilidade: uma questão de gênero. Trabalho (En) Cena, 2(2),18-38.

Trentini, M., Madureira, V. S. F, Silva, D. G. V. \& Paim, L. (2018). Pesquisa convergente assistencial e concepções sobre masculinidade. In Araújo, J. S. \& Zago, M. M. F. (Org.). Pluralidade masculina: contribuições para pesquisa em saúde do homem. PR:CRV.

World Health Organization. (2020). Coronavirus disease (COVID-2019) situation reports. https://www.who.int/dg/speeches/detail/who-director-general-sopening-remarks-at-the-media-briefing-on-Covid-19---11-march-2020. 